\title{
Effect of hole drilling at the overlap on the strength of single-lap joints
}

\author{
A.M.G.Pinto, R.D.S.G. Campilho, I.R. Mendes, S.M. Aires, A.P.M. Baptista
}

\begin{abstract}

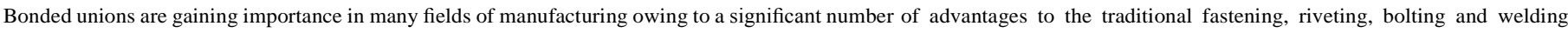

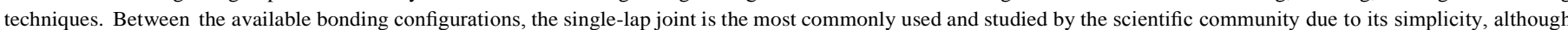

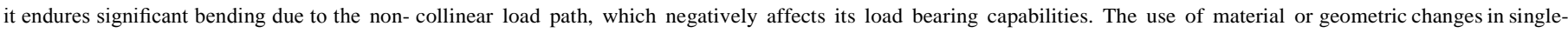

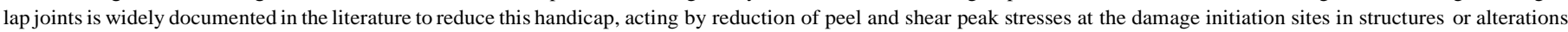

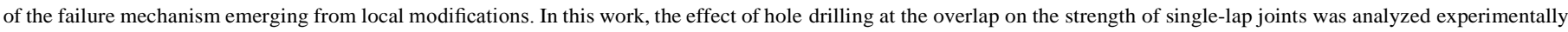

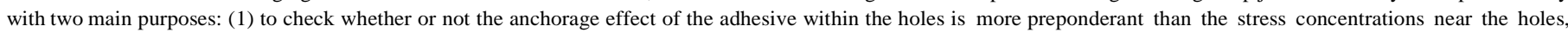
arising from the sharp edges, and modification of the joints straining behaviour (strength improvement or reduction, respectively) and

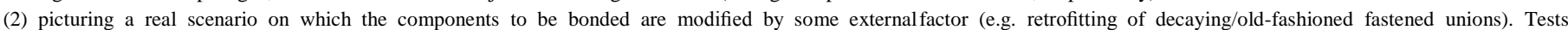

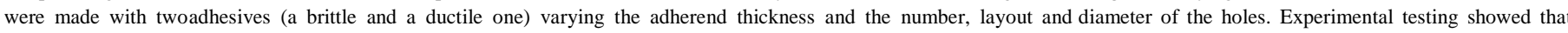
the joints strength never increases from theun-modified condition, showing a varying degree of weakening, depending on the selected adhesiveand hole drilling configuration.
\end{abstract}

\section{Keywords}

Epoxy/epoxides, Aluminium and alloys, Lap-shear, Joint design, Experimental testing

\section{Introduction}

Bonded unions are gaining importance in many fields of industry and manufacturing owing to a significant number of advantages to the traditional fastening, riveting, bolting and welding techniques. These include the uniform stress distributions along the width, possibility to joint different materials, improved fatigue and damping characteristics and reduced cost. Apart from this, adhesive bonded joints are becoming more and more efficient owing to increasing research and development in their microstructure, offering higher peel and shear strengths combined with larger ductility up to failure, which often results in stronger unions than the parent materials [1]. Amongst the disadvantages are the requirement of surface prepara- tion, vulnerability to extreme environmental conditions and varying properties depending on the manufacturing/curing conditions. Between the available bonding configurations, the single-lap joint is the most commonly used and studied by the scientific community due to its simplicity, although it endures significant bending due to the non-collinear load path. This eccentricity is responsible for peel peak stresses at the overlap edges which, added to the differential deformation effects along the overlap responsible for shear peak stresses, negatively impact on the joints effectiveness [2]. Other available configurations include the double-lap, stepped and scarf joints that provide improved stress distributions but are more complicated to manufacture. Owing to the aforementioned stress concentration issues in single-lap joints, much attention has been paid to the development of innovative techniques to surpass this limitation. These strength improvement techniques can be divided in to two major groups: geometric and material modifications, whichpositively affect the joints behaviour mostly by two mechanisms:reduction of peel and shear peak stresses at the critical regions (usually near sharp geometry changes) [3,4] or modification of the failure mechanism emerging from local changes [5].

Material modifications mainly attempt to optimize the mate- rial stiffness along the overlap to suppress stress concentrations at the overlap edges. One of these techniques consists on the use of bi-adhesives along the bondline. By using a stiffer adhesive at the inner overlap region than at the edges, a larger amount of load is transmitted by the inner region of the bond and the joints strength is increased, especially for brittle adhesives [6-8]. 

Young's modulus $(E)$ grading of the adherends is another alter- native. Ganesh and Choo [9] used this technique by continuously varying the braiding angle of the adherends' composite fibres to produce a varying value of $E$ along the bond length that increased the joints strength. Finite Element simulations showed that shear peak stresses in the adhesive bond can be reduced by $20 \%$. Pinto et al. [10] showed by a Finite Element (FE) stress and failure analysis that increasing the stiffness of the adherends materials in single-lap joints leads to a reduction of the joint bending, which diminished stresses at the overlap edges and, consequently, increased the strength of thejoints.

Geometric alterations are widely used to increase the strength of single-lap joints. Adhesive fillets at the overlap edges are one of the most widespread solutions, redistributing stresses at the overlap edges and, as a result, increasing the strength of the joints [11-13]. For maximum effect of this modification, i.e. minimizing peel and shear peak stresses at the overlap edges, fillets comprise all the patch thickness [14]. Tsai and Morton [15] addressed the influence of filleting on composite single-lap joints by plotting shear strains near the fillet using the Moire' Inter- ferometry Method. The analysis showed a reduction of shear strains, and also of peel and shear stresses at the fillet region, subsequently increasing the joint strength. An improvement of this procedure was proposed by You et al. [16], which tested experimentally the use of fillets incorporating steel wires and wedges with varying shapes in single-lap joints with steel adherends. Three different shape/size combinations for the steel elements were considered, including circular and triangular shaped elements. An approximately $45 \%$ improvement was found for the joints tensile strength using a circular steel wire, with smaller improvements resulting from the other shapes. Adherend tapering at the overlap region is also documented in the litera- ture. Sancaktar and Nirantar [17] concluded that adherend taper- ing significantly reduces peel and shear peak stresses in single-lap joints, which yields a strength improvement. These results are fully consistent with the work of Boss et al. [18]. Another solution consists on bending the adherends at the bonding edge for the optimization of the stress distributions by elimination of the joints eccentricity. This technique was analysed by photoelasticity by McLaren and MacInnes [19], showing its effectiveness for the uniformization of the adhesive stresses along the bondline. Fessel et al. [20] performed an experimental and FE study regarding tensile loaded steel single-lap joints, with emphasis on wavy and bent geometries. These modifications diminished peel and shear peak stresses at the overlap edges (from $8 \%$ to $40 \%$ compared to the flat geometry, depending on the adherends material and geometric parameters such as the overlap length). Campilho et al. [21] studied singlelap joints bonded with a brittle and a ductile adhesive to assess the strength improvement by the adherend bending technique, considering different degrees of eccentricity, including absence of eccentricity, for the optimization of the joints. Bending of the adherends showed to be quite positive in reducing peel peak stresses at the overlap edges, which gradually diminished by increasing the adherends bending. Shear peak stresses also turned less significant at the overlap edges with the increase of the adherends bending. Experimental and FE results showed a great advantage in using this technique for the brittle adhesive, conversely to the joints with the ductile adhe- sive. Actually, these were not so much affected by the proposed technique since ductile adhesives redistribute stress in the bond and limit the effect of peak stresses. Ávila and Bueno [22] tested a wavy geometry for singlelap joints with composite adherends

(sinusoidal adherends shape at the overlap induced by the fabrication process). The authors concluded that this solution increased on nearly $40 \%$ the strength of the flat joints because of the elimination of the peel and shear peak stresses at the edges of the adhesive layer. Identical results found by Zeng and Sun [23] reported a large strength improvement of the joints emerging from the suppression of peel stresses and development of com- pressive through-thickness stresses at the overlap edges. Sancak- tar and Simmons [24] tested an adherend notching technique at the overlap edges on aluminium single-lap joints under tension. The FE study carried out showed benefits in terms of stress distributions, namely a $66 \%$ reduction on peel peak stresses. Despite this fact, experimental testing revealed a strength improvement of only $8 \%$ compared to the standard single-lap joints. The numerical work of Yan et al. [25] focused on a similar notching technique by studying the influence of the length and depth of a parallel slot at the mid-region of the bond length. By using this technique, shear and peel peak stresses at the bond edges markedly decreased with a corresponding increase of load transfer at the usually lightly loaded inner region of the bond. Peel stresses were suppressed at the joint edges, which can lead to a strength improvement.

In this work, the effect of hole drilling in the adherends on the strength of single-lap joints was analyzed experimentally with two main purposes: (1) to check whether or not the anchorage effect of the adhesive within the holes is more preponderant than the stress concentration effect near the holes arising from the sharp edges and modification of the joints straining behaviour (strength improvement or reduction, respectively) and (2) pictur- ing a real scenario on which the components to be bonded are modified by some external factor (e.g. retrofitting of decaying/ old-fashioned fastened unions). Tests were made with two adhesives (a brittle and a ductile one) varying the adherend thickness and the number, layout and diameter of the holes.

\section{Experimental work}

\subsection{Materials}

The aluminium alloy for the adherends and the two adhesives selected for this study were properly characterized for a percep- tion of their behaviour and interpretation of the experimental results, presented further in this work. The adherends were fabricated from the high strength aluminium alloy AW6082 T651, showing a manufacturer specified strength of $340 \mathrm{MPa}$ achieved by artificial ageing at approximately $1801 \mathrm{C}$. This alumi-

nium alloy was previously characterized [26] using dogbone specimens. The stress-strain (S-e) plots, obtained through tensile

testing following the principles specified in the standard ASTM- E8M-04 [27], showed a nearly elastic-perfectly plastic law with the following mechanical properties: $E$ of $70.0770 .83 \mathrm{GPa}$, ten-

sileyield stress $\left(\mathrm{S}_{\mathrm{y}}\right)$ of $261.6777 .65 \mathrm{MPa}$, tensile failure strength

$\left(\mathrm{s}_{\mathrm{f}}\right)$ of $32470.16 \mathrm{MPa}$ and tensile failure strain $\left(\mathrm{e}_{\mathrm{f}}\right)$ of

$21.7074 .24 \%$. The two adhesives selected for this work, Araldite ${ }^{\mathrm{s}}$ AV138 and Araldite $^{\mathrm{s}}$ 2015, were also characterized in tension and shear for the determination of all relevant parameters such as

$E$, shear modulus $(G), \mathbf{S}_{\mathrm{y}}, \mathbf{S}_{\mathrm{f}}$ and $\mathrm{e}_{\mathrm{f}}$ [28]. The tensile characteriza-

tion for both adhesives was carried out by bulk specimens with the typical dogbone shape, fabricated according to the French standard NF T 76-142 [29] and da Silva and Adams work [30], which provides guidelines to produce high quality specimens, without voids. The fabrication of the specimens was achieved in a sealed mould by application of pressure and temperature according to the manufacturer indications. The adhesive was poured in a silicone mould with $2 \mathrm{~mm}$ thickness to produce a bulk plate that is machined to produce two dogbone specimens each. On the other hand, shear characterization of the two adhesives was achieved by Thick Adherend Shear Tests (TAST) with the proce- dure described in the standard ISO 11003-2:1999 [31]. For the 
TAST tests, the adherends were made of DIN Ck 45 steel, and cohesive failures of the adhesive were achieved on account of a proper surface preparation involving grit-blasting and cleaning with acetone. The results from these tests showed a brittle

behaviour for the Araldite ${ }^{\mathrm{s}} \mathrm{AV} 138\left(\mathrm{e}_{\mathrm{f}} \mathbf{E} 1.2 \%\right.$ and shear failure

strain, $\mathrm{g}_{\mathrm{f}}$, of approximately $7.8 \%$ ) and a largely ductile behaviour for the Araldite $^{\mathrm{s}} 2015\left(\mathrm{e}_{\mathrm{f}} \mathbf{E} 4.8 \%\right.$ and $\left.\mathrm{g}_{\mathrm{f}} \mathbf{E} 44 \%\right)$, with a high degree

of plasticization at a constant stress prior to failure. The failure strength of the AV138 was nearly the double than that of the 2015. The results also showed bigger data dispersion for the Araldite ${ }^{\mathrm{s}}$ AV138 as, since it is very brittle, the results are more dependent on fabrication flaws [28]. Table 1 reviews the pre- viously collected data on these materials (the yield strength was computed considering a plastic deformation of $0.2 \%$ for both adhesives) [28].

Table 1

Properties of the adhesives Araldites AV138 and 2015 [28].

\begin{tabular}{lcc}
\hline Property & AV138 & 2015 \\
\hline Young's modulus, $E(\mathrm{GPa})$ & 4.8970 .81 & 1.8570 .21 \\
Poisson's ratio, $\mathrm{n}^{\mathrm{a}}$ & 0.35 & 0.33 \\
Tensile yield strength, $\mathrm{Sy}(\mathrm{MPa})$ & 36.4972 .47 & 12.6370 .61 \\
Tensile failure strength, $\mathrm{Sf}(\mathrm{MPa})$ & 39.4573 .18 & 21.6371 .61 \\
Tensile failure strain, $\mathrm{e}_{\mathrm{f}}(\%)$ & 1.2170 .10 & 4.7770 .15 \\
Shear modulus, $G(\mathrm{GPa})$ & 1.5670 .01 & 0.5670 .21 \\
Shear yield strength, $\mathrm{t}_{\mathrm{y}}(\mathrm{MPa})$ & 25.170 .33 & 14.671 .3 \\
Shear failure strength, $\mathrm{t}_{\mathrm{f}}(\mathrm{MPa})$ & 30.270 .40 & 17.971 .8 \\
Shear failure strain, $\mathrm{g}_{\mathrm{f}}(\%)$ & 7.870 .7 & 43.973 .4 \\
\hline
\end{tabular}

\subsection{Joint geometry}

In this work, single-lap joints were tested without holes (standard, unmodified configuration) and with holes at the overlap region. Three different modified configurations were evaluated to check under different conditions whether the hole drilling technique improves the strength of the joints due to anchorage effects, or if it reduces the strength because of stress concentrations and deformation effects arising in the vicinity of the drilled regions. Configuration 1, shown in Fig. 1, corresponds to the standard (unmodified) single-lap joint. All joints showed the same values of length between gripping points $\left(L_{\mathrm{T}} 1 / 4160 \mathrm{~mm}\right)$, thickness of the adherends $\left(t_{\mathrm{S}} 1 / 42\right.$ and $3 \mathrm{~mm})$, adhesive thickness $\left(t_{\mathrm{A}} 1 / 40.2 \mathrm{~mm}\right)$, overlap length $\left(L_{0} 1 / 415 \mathrm{~mm}\right)$,

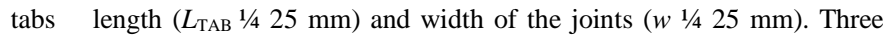
other configurations were tested, considering different layouts for the holes. Configuration 1, without any modifications, will be used for strength comparison purposes with the modified joints and evaluation of the modified configurations.

For the modified joints, each configuration comprises holes

with diameter of $1\left(f_{1}\right)$ and $2 \mathrm{~mm}\left(\mathrm{f}_{2}\right)$ and values of $t_{\mathrm{S}}$ of 2 and

$3 \mathrm{~mm}$. In configuration 2 (Fig. 2), a set of three equidistant holes, separated by $7 \mathrm{~mm}$, was drilled in one of the adherends trans- versely to the specimens length at the middle of the overlap. For configuration 3 (Fig. 3), the set of three holes, equally $7 \mathrm{~mm}$ apart, was considered on both adherends at a distance of 5 $\mathrm{mm}$ to the respective joint edge, such that the assembled joint is modified by two sets of holes separated by $5 \mathrm{~mm}$ in the length direction of the joint. Configuration 4 (Fig. 4) follows the same principles of configuration 3, i.e. hole drilling of one set of holes on both adherends, but these sets are at a distance of $10 \mathrm{~mm}$ to the respective adherend edge. As a result, the sets of holes are also

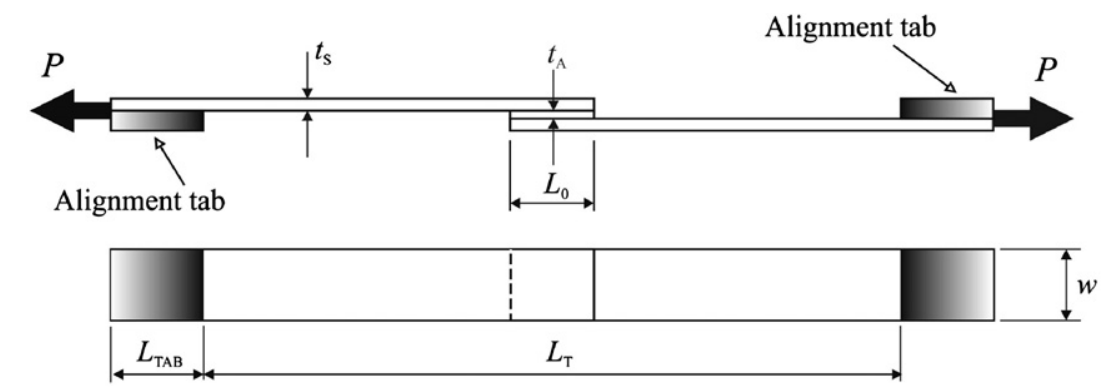

Fig. 1. Configuration 1: single-lap joint without holes in overlap zone (dimensions in $\mathrm{mm}$ ).

a

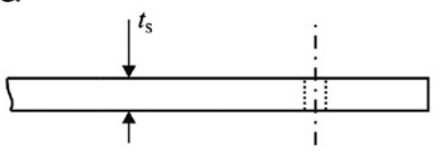

b

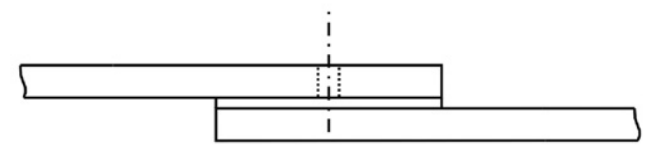

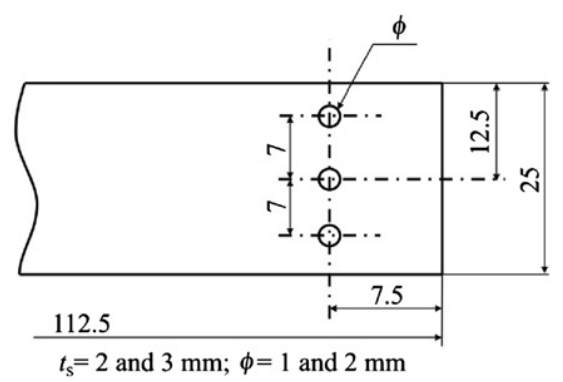

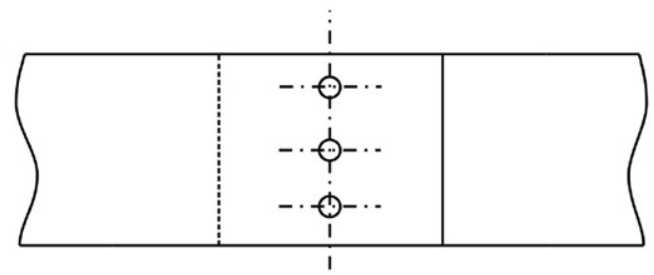

Fig. 2. Configuration 2: holes layout in the upper adherend (a) and in the joint (b) (dimensions in $\mathrm{mm}$ ). 
a
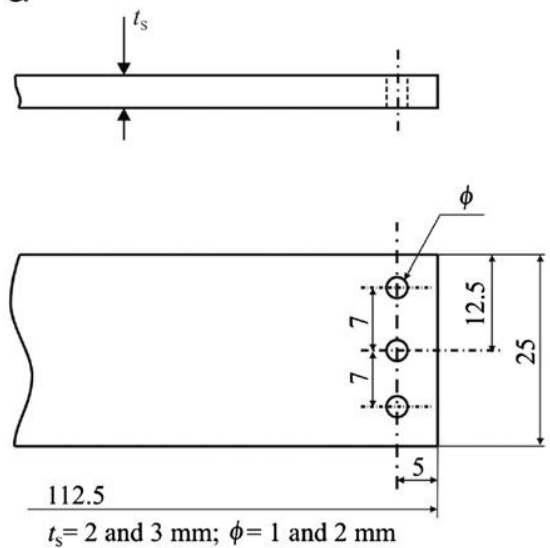

b
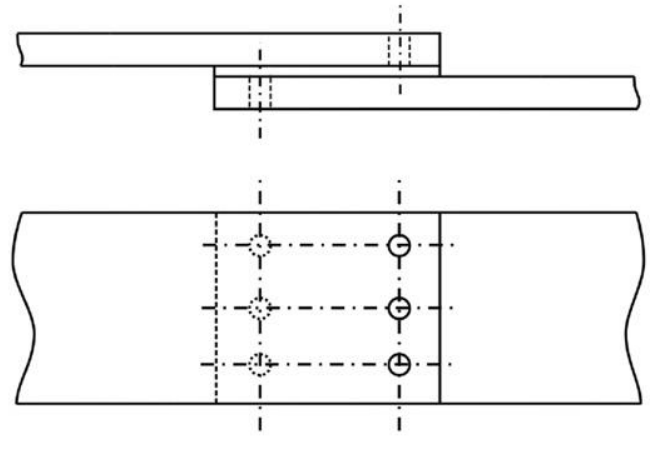

Fig. 3. Configuration 3: holes layout in the adherends (a) and in the joint (b) (dimensions in $\mathrm{mm}$ ).

a
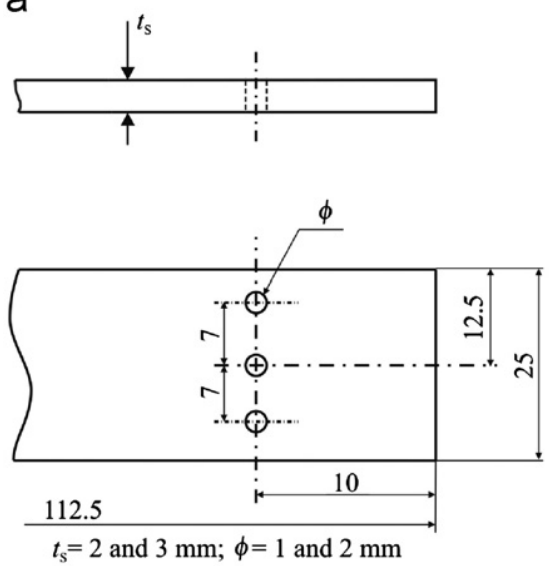

b
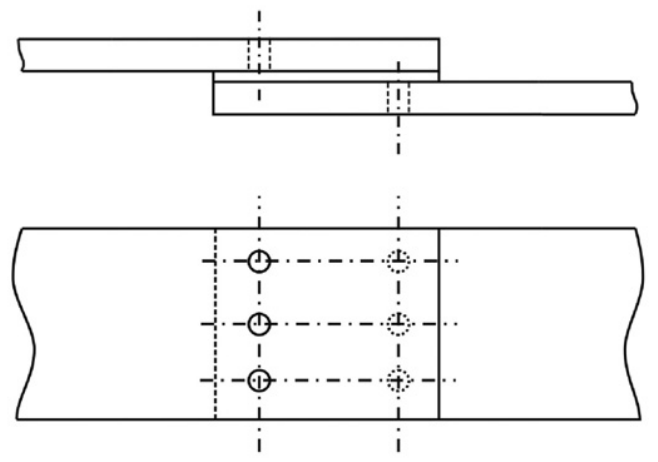

Fig. 4. Configuration 4: holes layout in the adherends (a) and in the joint (b) (dimensions in $\mathrm{mm}$ ).

separated by $5 \mathrm{~mm}$, but in configuration 4 the drilled holes in each adherend are placed at a region of larger magnitude of longitudinal stresses. Thus, they are prone to show a bigger influence on the stress distributions along the bondline.

\subsection{Joint manufacture}

The adherends were machined from laminated sheets using high-speed steel mills. The bonding surfaces were initially degreased with acetone and grit blasted with corundum sand. After the mechanical process of grit-blasting to remove the surface oxide layer and contaminations, the surfaces were again cleaned with acetone, and allowed to dry before application of the adhesive. The chosen value of $t_{\mathrm{A}}$ was controlled by calibrated spacers below the upper adherend whose thickness was defined individually for each specimen as $t_{\mathrm{S}}+t_{\mathrm{A}}$. The cure of the adhesive was carried out at room temperature and the specimens were left at ambient conditions for one week prior to testing. The adhesive excess at the overlap edges and at the holes was always removed manually slightly before complete curing, leaving the holes completely filled with adhesive (Fig. 5 shows a detail of the bonding process: before (a) and after (b) removal of the adhesive excess). Tabs at the ends of single-lap joints were bonded to improve alignment, as shown in Fig.1. a

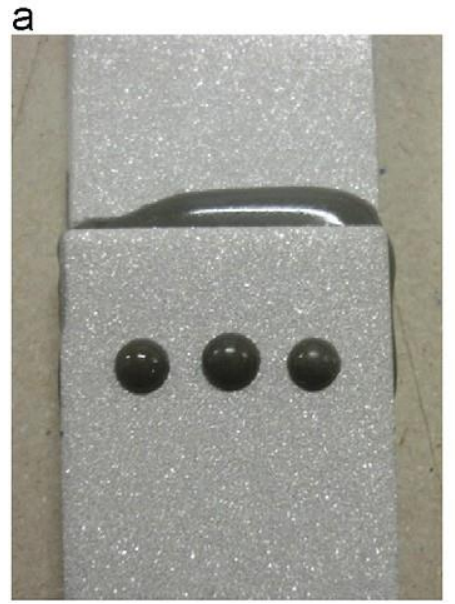

b

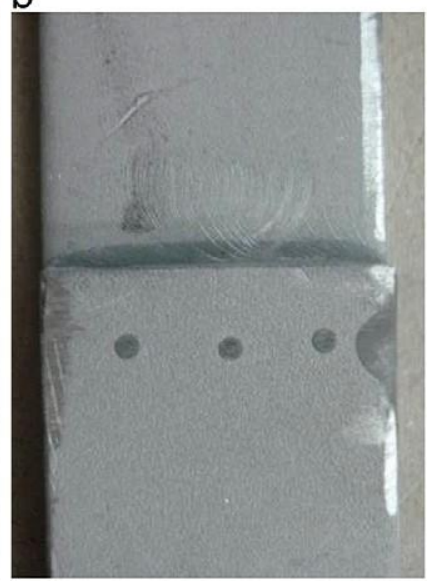

Fig. 5. Detail of the bonding process: before (a) and after (b) removal of the adhesive excess.

\subsection{Test procedure}

The joints were tested on a screw-driven electro-mechanical testing machine (Shimadzu AG-X 100) with a load cell of $100 \mathrm{kN}$. Data recording was carried out at $5 \mathrm{~Hz}$ for the load and testing machine grips displacement. All specimens were tested at room 
a

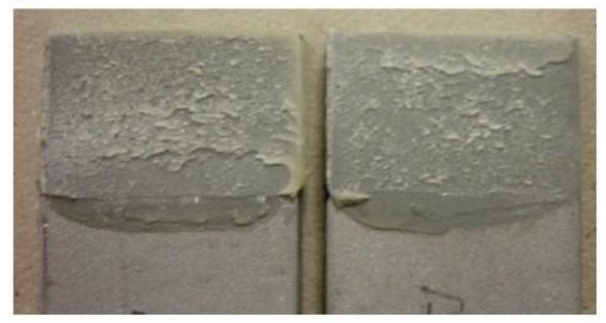

C

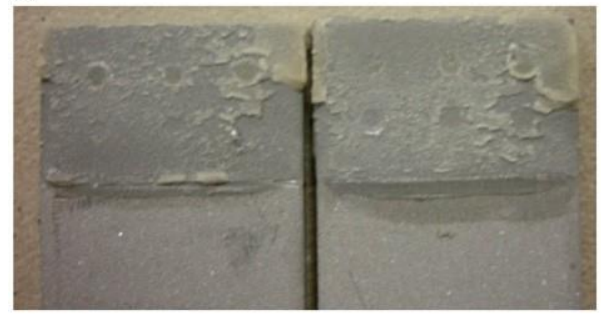

b

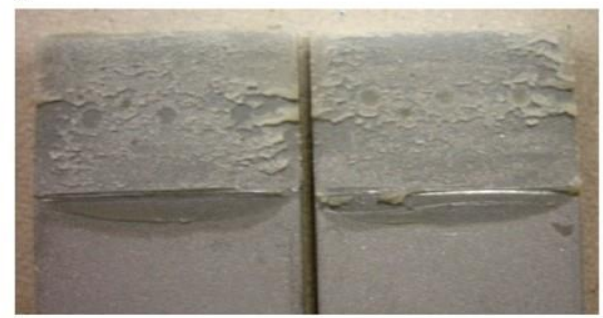

d

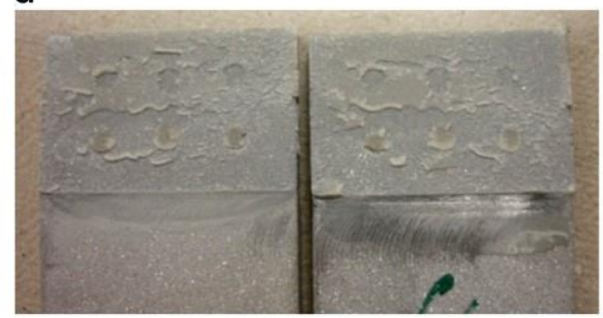

Fig. 6. Fracture surfaces for the joints bonded with Araldite ${ }^{\mathrm{s}} 2015$ (ts $\left.1 / 43 \mathrm{~mm}\right)$, considering configuration 1 (a), configuration 2 and $\mathbf{f}_{2}$ (b), configuration 3 and $\mathbf{f}_{2}$ (c) and configuration 4 and $\mathbf{f}_{2}$ (d).

a

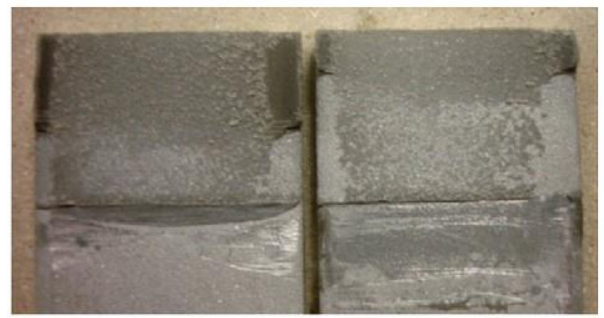

C

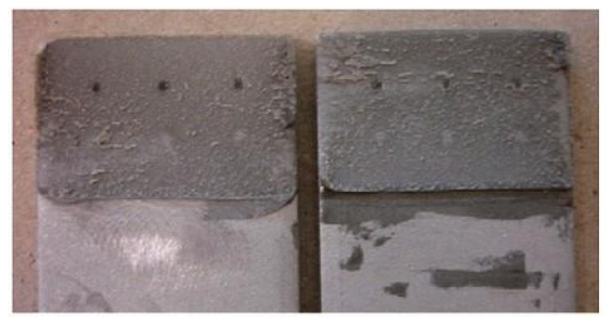

b

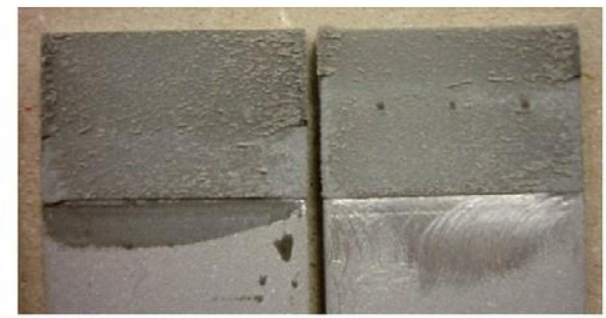

d

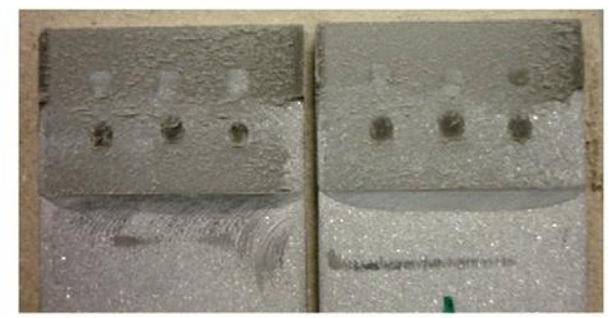

Fig. 7. Fracture surfaces for the joints bonded with Araldite ${ }^{\mathrm{s}} \mathrm{AV} 138\left(t_{\mathrm{s}} 1 / 43 \mathrm{~mm}\right)$, considering configuration 1 (a), configuration 2 and $\mathbf{f}_{1}$ (b), configuration 3 and $\mathbf{f}_{1}$ (c) and configuration 4 and $\mathbf{f}_{2}$ (d).

temperature (approximately $231 \mathrm{C}$ ), relative humidity of $80 \%$ and at a testing speed of $1 \mathrm{~mm} / \mathrm{min}$. Four valid results were obtained for each condition. The failure modes of the joints were assessed by visual inspection afterfailure.

\section{Results}

Fracture of the joints always occurred by cohesive failure of the adhesive layer, which certifies the surface preparation tech- niques for bonding, described previously in Section 2.3. Fig. 6 shows the fracture surfaces for the joints bonded with Araldite ${ }^{\mathrm{s}}$

2015, considering configuration 1 (a), configuration 2 and $f_{2}$ (b), configuration 3 and $f_{2}(c)$ and configuration 4 and $f_{2}(d)$. Fig. 7

corresponds to the adhesive Araldite ${ }^{\mathrm{s}}$ AV138, relating to config- uration 1 (a), configuration 2 and $\mathbf{f}_{1}$ (b), configuration 3 and $\mathbf{f}_{1}$

(c) and configuration 4 and $\mathbf{f} 2$ (d). Both figures relate to $t_{\mathrm{S}} 1 / 43 \mathrm{~mm}$. Figs. 8 and 9 report on the $P-\mathrm{d}$ curves for the joints bonded with the adhesive Araldite ${ }^{\mathbf{S}} 2015$ and Araldite $^{\mathbf{S}}$ AV138

$\left(t_{\mathrm{S}} 1 / 43 \mathrm{~mm}\right)$, respectively, considering configuration 1 (a) and configuration 4 and $\mathbf{f}_{2}$ (b). These figures show a linear behaviour up to failure for the adhesive Araldites AV138, due to its

brittleness and corresponding smaller load bearing capabilities of the joints, as opposite to the $P-\mathrm{d}$ curves of the adhesive Araldites 2015 that show signs of adhesive and adherend

plasticization before the maximum load sustained by the speci- mens $\left(P_{\max }\right)$ is attained. Comparison between these two figures also emphasizes the lower value of $E$ for the adhesive Araldite ${ }^{\mathrm{s}} 2015$ (Table 1), which results on a bigger failure displacement.

Although it is expected that the drilling procedure reduces the global stiffness of the joints [25], this was not perceptible in the $P$-d curves for any condition. This behaviour is imputed to the

larger value of $E$ of the adherends, which renders any geometric modification in the adherends less significant, compared to the adhesive characteristics. Figs. 10-13 represent the average and standard deviation results of $P_{\max }$ for the different configurations 
a

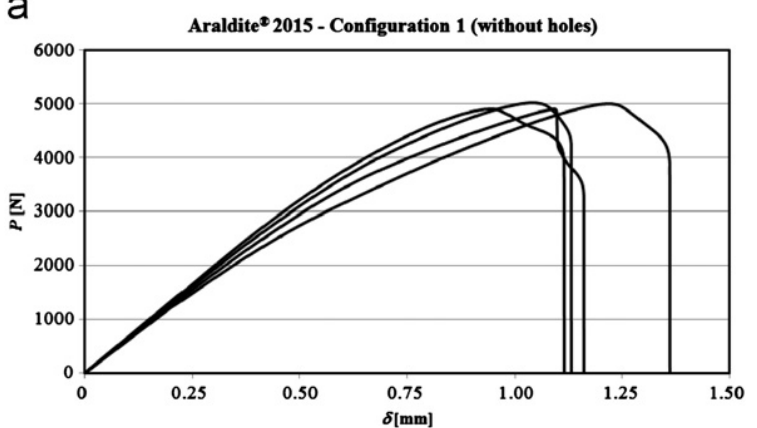

b

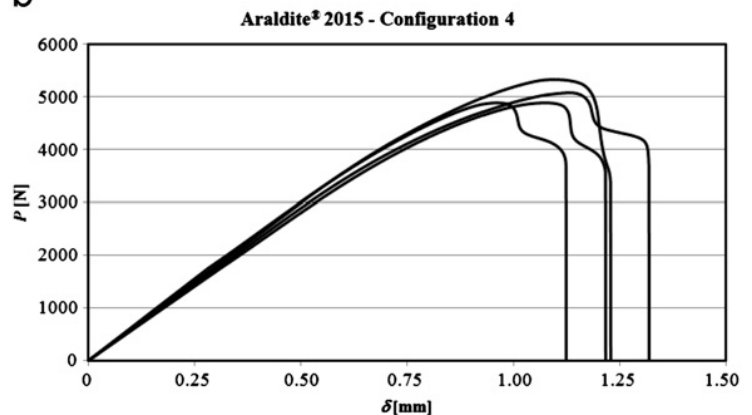

Fig. 8. Experimental $P$-d curves for the joints bonded with Araldite $2015\left(t \mathrm{~s}^{1 / 4} 3 \mathrm{~mm}\right)$, considering configuration 1 (a) and configuration 4 and $\mathbf{f}_{2}$ (b).

a

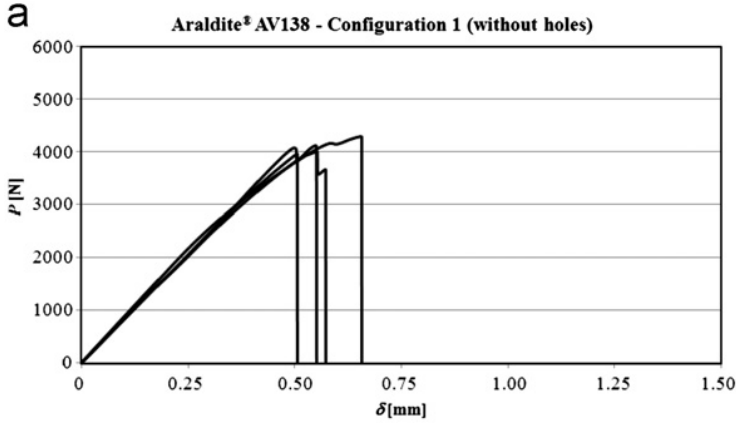

b

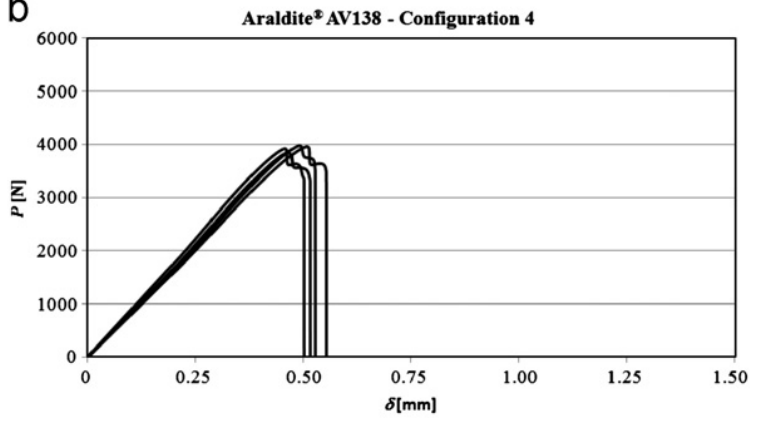

Fig. 9. Experimental $P-\mathrm{d}$ curves for the joints bonded with Araldite ${ }^{\mathrm{s}}$ AV138 $\left(t_{\mathrm{s}}{ }^{1 / 43} \mathrm{~mm}\right)$, considering configuration 1 (a) and configuration 4 and $\mathbf{f}_{2}$ (b).

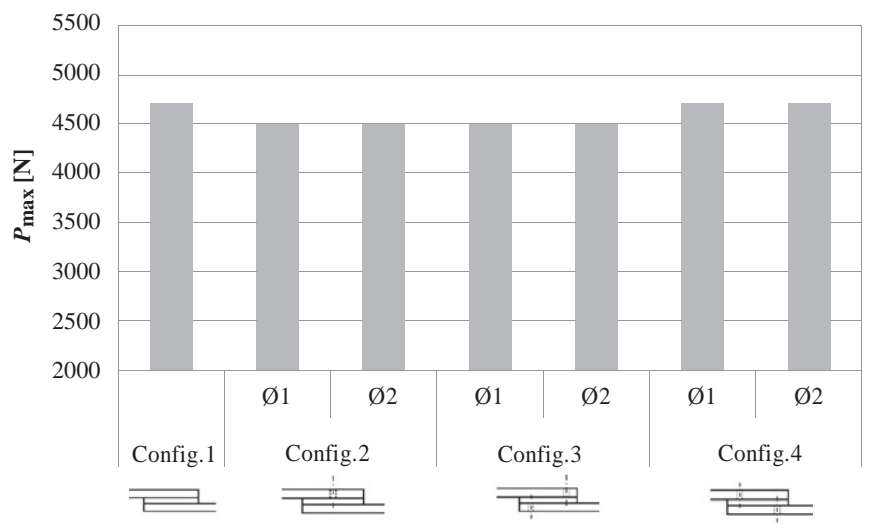

Fig. 10. $P_{\max }$ for the different configurations (Araldite $\mathrm{s} 2015, t_{\mathrm{s}} 1 / 42 \mathrm{~mm}$ )

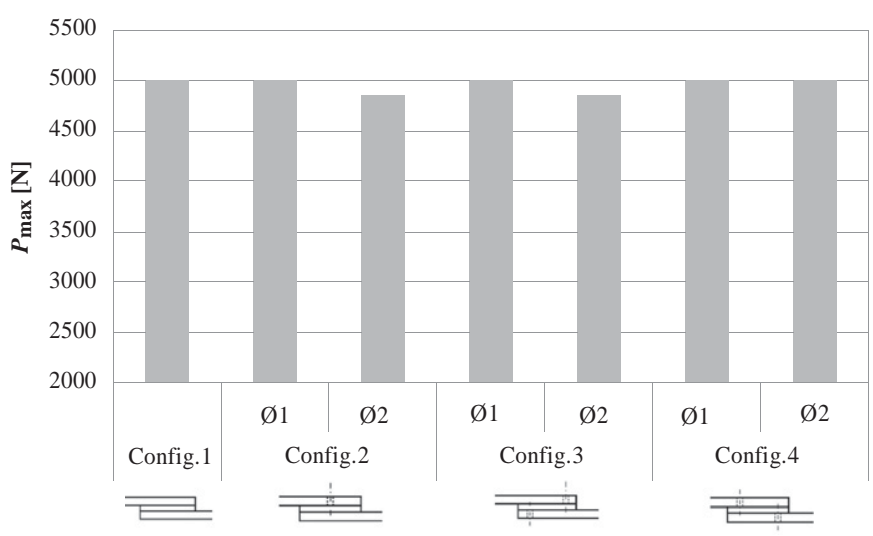

Fig. 11. $P_{\max }$ for the different configurations (Araldite ${ }^{\mathrm{s}} 2015, t \mathrm{~s}^{1 / 4} 3 \mathrm{~mm}$ )

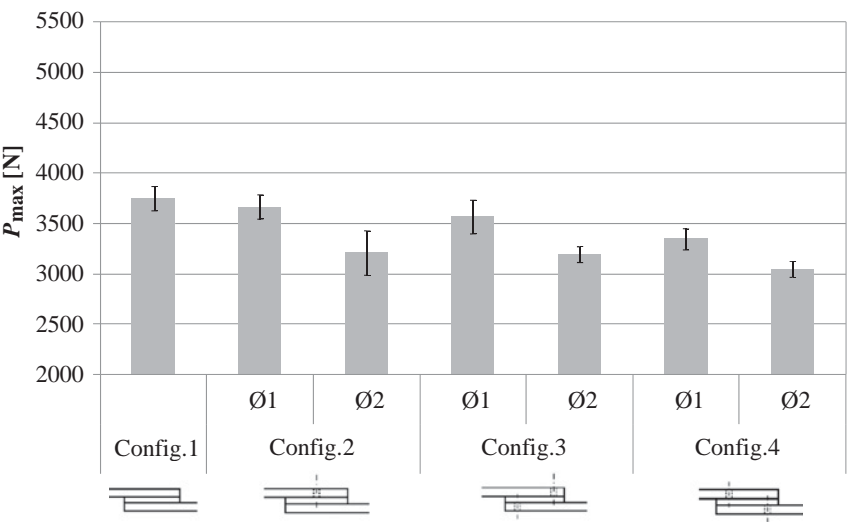

Fig. 12. $P_{\max }$ for the different configurations (Araldite ${ }^{\mathrm{s}}$ AV138, $t \mathrm{~s}^{1 / 42} \mathrm{~mm}$ ).

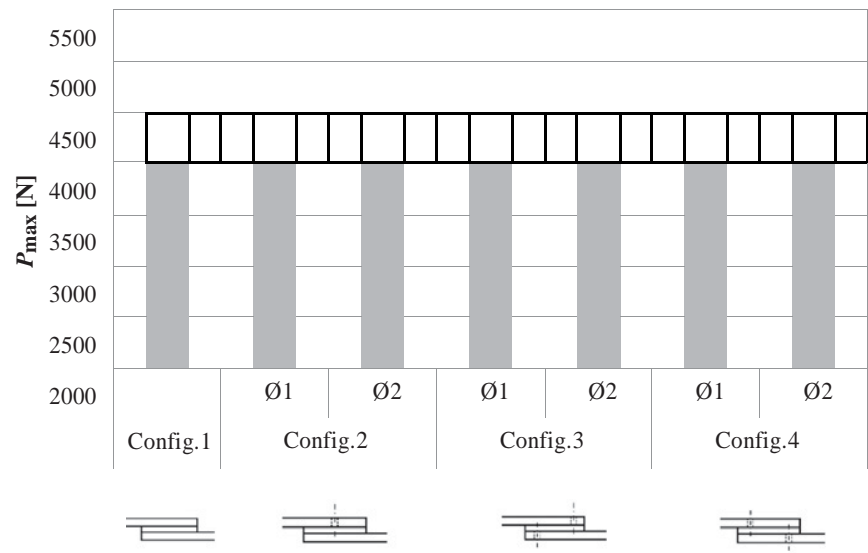

Fig. 13. $P_{\max }$ for the different configurations (Araldite $\mathrm{s}^{\mathrm{s}} \mathrm{AV} 138, t \mathrm{~s}^{1 / 43} \mathrm{~mm}$ ). 
of joints and values of $\mathbf{f}$ tested. Fig. 10 summarizes the results for the adhesive Araldite $^{\mathrm{s}} 2015$, considering $t_{\mathrm{S}} 1 / 42 \mathrm{~mm}$. The best results were found for the un-modified single-lap joint, with very close results for all the modifications tested. Nonetheless, a small reduction was found for some of the conditions (maximum

reduction of $4.5 \%$ from configuration 1 to configuration $3, \mathbf{f}_{1}$ ).

These results are justified by the ductile characteristics of the Araldite 2015, causing the joints to fail by global yielding [32], which makes the stress concentrations near the holes and the larger longitudinal deformation of the adherends due to the weakened section irrelevant for the strength of the joints. Actu- ally, although an increase of the stress concentrations in the adhesive layer at the overlap edges is expected under elastic loading [25], failure should occur at a practically constant level of shear stresses, which justify the nil influence of these modifications for the adhesive Araldite ${ }^{\mathbf{s}}$ 2015. Fig. 11 relates to the same adhesive, but considering $t_{\mathrm{S}} 1 / 43 \mathrm{~mm}$. Also in this case the difference between all of the testing conditions is very small, whose reasoning is similar to the previous condition, which means that the effect of the holes for this particular type of adhesive is negligible (maximum reduc-

tion of $2.6 \%$ from configuration 1 to configuration $3, \mathbf{f}_{2}$ ). By

comparing with Fig. $10\left(t_{\mathrm{s}}^{1 / 42} \mathrm{~mm}\right)$, an improvement of strength by increasing $t_{\mathrm{S}}$ was found $(5.5 \%$ for configuration 1$)$, which can be explained by the increasing bending stiffness of the adherends and corresponding reduction of the peel effects [10]. In fact, the adherends opposed curvature resulting from the asymmetry of loading in single-lap joints results on a separation of the adherends at the overlap edges and compression in-between. It is also common knowledge that this effect is reduced by increasing the adherends stiffness, due to a smaller bending of the adherends [33,34]. Fig. 12 concerns the adhesive Araldite ${ }^{\mathrm{s}}$ AV138 and $t_{\mathrm{s}} 1 / 42 \mathrm{~mm}$. Unlike the previous results, for the AV138 the effect of the holes is significant, as the strength always diminishes from the standard single-lap joint (maximum reduction of $18.7 \%$ from configuration 1 to configuration $4, \mathbf{f}_{2}$ ). This is related to the brittleness of the adhesive Araldite ${ }^{\mathrm{s}}$ AV138, which makes $P_{\max }$ extremely sensitive to peak stresses at the bonding region arising from the higher longitudinal deformations in

the adhesive. The stress concentrations exist at the overlap edges and in the vicinity of the holes. Fig. 13 reports a similar scenario, but considering $t_{\mathrm{S}} 1 / 43 \mathrm{~mm}$. In this situation, opposite to $t_{\mathrm{S}} 1 / 42 \mathrm{~mm}$, a smaller reduction of the failure load of the standard joint was found (maximum reduction of $4.0 \%$ from configuration 1 to config-

uration $4, \mathbf{f}_{2}$ ), but following overall the same tendency. This is precisely due to the higher value of $t_{\mathrm{S}}$ that reduces the harmful effect of the holes as the deformation at the weakened region and globally along the overlap length is largely reduced. Moreover, since peel

1 - Bigger longitudinal deformation of the upper adherend

2 - Bigger longitudinal shearing of the upper adherend to the lower adherend
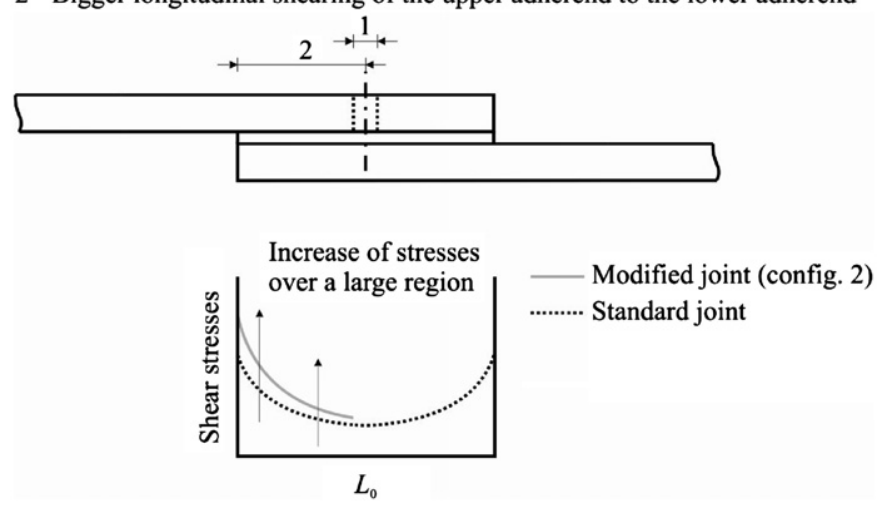

Fig. 14. Sketch of the deformation behaviour and shear stresses along the bond- line for configuration 2 .

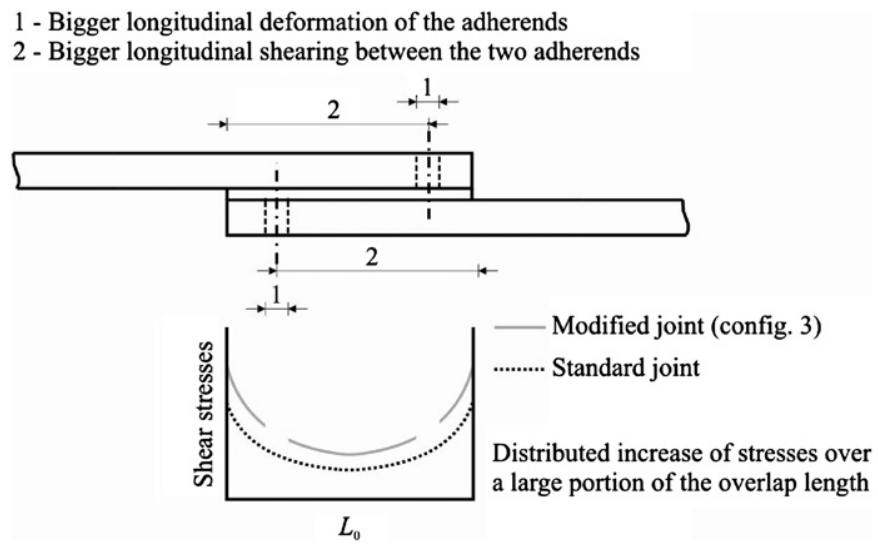

Fig. 15. Sketch of the deformation behaviour and shear stresses along the bond- line for configuration 3 .

1 - Bigger longitudinal deformation of the adherends

2 - Bigger longitudinal shearing between the two adherends

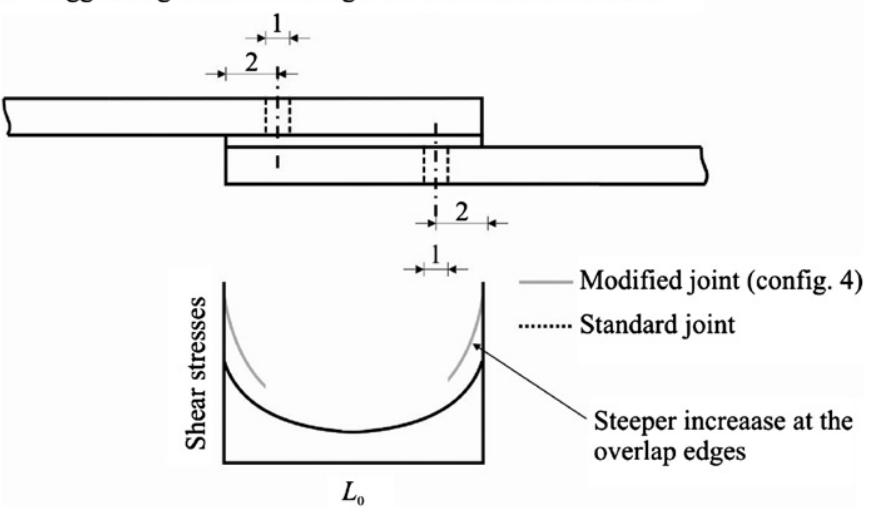

Fig. 16. Sketch of the deformation behaviour and shear stresses along the bond- line for configuration 4 .

effects also diminish [10], the increase of shear stresses is not so detrimental to the global behaviour of the joints. Equally to the Araldite ${ }^{\mathbf{s}} 2015$, the strength is higher for $t_{\mathrm{S}} 1 / 43 \mathrm{~mm}$ ( $8.9 \%$ of strength improvement for configuration 1), due to the reduction of peel effects at the overlap region [10]. Both in Figs. 12 and 13, increasing

the value of $\mathbf{f}$ furtherreduces $P_{\max }$, by largerdeformation effects

due to the smaller cross-section at the drilled region.

Taking a closer look at each one of the modified configurations for the adhesive Araldite $^{\text {s }}$ AV138 (Figs. 12 and 13), it is found that configurations 2 and 3 behave similarly, while configuration

4 clearly shows a further reduction of performance to the standard single-lap joint. Figs. 14-16 picture the deformation behaviour of the joints for configurations 2, 3 and 4, respectively, and a simplified sketch of the changes in shear stresses arising from these modifications. For all configurations, a bigger long- itudinal straining is assumed at the drilled region, due to the respective reduction of cross-sectional area. For each drilled adherend, it is considered that each region to the opposite side of the adherend edge endures larger shearing effects with the other adherend, due to this localized increased deformation at the modified region. Fig. 14, related to configuration 2 , clarifies the mentioned assumptions, showing an increase of shear stress along the adhesive bond that are distributed over a large area (almost half of the overlap). Yan et al. [25] testified a similar behaviour of shear stresses for notched single-lap joints by 
introducing a slot parallel to the bondline that gives an identical effect on stresses. As a result of the gradual increase of stresses, the value of $P_{\max }$ is moderately affected. Configuration 3 (Fig. 15) is under an identical scenario, i.e. the increased shearing between the two adherends extends over a large portion of the overlap, giving similar results of $P_{\max }$ to configuration 2. On the other hand, configuration 4 (Fig. 16) concentrates the higher shear- ing effects between the two adherends at a very restricted region at the overlap edges, thus with a higher magnitude of peak stresses. Due to the brittleness of the adhesive, these peak stresses are not accommodated, and $P_{\max }$ is lower than for con-figurations 2 and 3 .

\section{Concluding remarks}

In this work, the effect of hole drilling in the adherends on the strength of single-lap joints was analyzed experimentally. Tests were made with two adhesives (a brittle and a ductile one) varying the adherends thickness, and number, layout and diameter of the holes. The holes were filled by adhesive as a result of the bonding process, which increased the anchorage effect of the adhesive at this typically lightly stressed region. The work carried out aimed to check whether or not the anchorage effect of the adhesive is more preponderant than the stress concentration effects in the vicinity of the holes arising from the disruption of geometry and modification of the joints straining behaviour. Analysis of the experimental data showed that hole drilling never benefits the strength of the standard (un-modified) single-lap joint, which means that stress concentra- tions and larger deformation effects surpass the effect of anchorage provided by the adhesive holes at a typical lightly loaded region of the adhesive, i.e. its inner region. For the adhesive Araldite ${ }^{\mathrm{s}}$ 2015, notwithstanding the layout and diameter of the holes and the adhesive thickness, the maximum load was always quite similar, showing only minor fluctuations (maximum reduction of $4.5 \%$ and $2.6 \%$ for the joints with adherend thickness of 2 and $3 \mathrm{~mm}$, respectively). This behaviour could be easily explained by the large ductility of this adhesive that causes the joints to fail by global yielding, cancelling possible harmful effects due to the drilled holes. On the other hand, large strength reductions were found for the adhesive Araldite ${ }^{\mathrm{s}}$ AV138 for an adherend thickness of $2 \mathrm{~mm}$ (maximum reduction of 18.7\%), although the joints strength was less affected for an adherend thickness of $3 \mathrm{~mm}$ (maximum reduc- tion of $4.0 \%$ ). This was accredited to the brittleness of the adhesive, which makes the failure load extremely sensitive to peak stresses at the bonding region and larger shearing effects due to bigger deformations. For an adherend thickness of 3 $\mathrm{mm}$, the smaller reduction of the failure load of the standard joint is due to the higher adherend thickness that reduces the harmful effect of the holes and diminishes peel stresses.

\section{Acknowledgement}

The authors would like to thank Instituto de Engenharia Mecânica e Gesta o Industrial (INEGI) for supporting the work.

\section{References}

[1] Ahn SH, Springer GS. Repair of composite laminates-I: test results. J ComposMater 1998;32:1036-74.
[2] Adams RD, Wake WC. Structural adhesive joints in engineering. London: Elsevier Applied Science Publishers Ltd.; 1984.

[3] Groth HL, Nordlund P. Shape optimization of bonded joints. Int J Adhes Adhes1991:11:204-12.

[4] You M, Yan ZM, Zheng XL, Yu HZ, Li Z. A numerical and experimental study of adhesively bonded aluminium single lap joints with an inner chamfer on the adherends. Int J Adhes Adhes 2008;28:71-6.

[5] Campilho RDSG, de Moura MFSF, Domingues JJMS. Using a cohesive damage model to predict the tensile behaviour of CFRP single-strap repairs. Int J Solids Struct 2008;45:1497-512.

[6] Pires I, Quintino L, Durodola JF, Beevers A. Performance of bi-adhesive bondedaluminium lap joints. Int J Adhes Adhes 2003;23:215-23.

[7] Fitton MD, Broughton JG. Variable modulus adhesives: an approach to optimized joint performance. Int J Adhes Adhes 2005;25:329-36.

[8] da Silva LFM, Lopes MJCQ. Joint strength optimization by the mixed adhesivetechnique. Int J Adhes Adhes 2009;29:509-14.

[9] Ganesh VK, Choo TS. Modulus graded composite adherends for single-lap bonded joints. J Compos Mater 2002;36:1757-67.

[10] Pinto AMG, Magalha es AG, Campilho RDSG, de Moura MFSF, Baptista APM. Single-lap joints of similar and dissimilar adherends bonded with an acrylicadhesive. J Adhes 2009;85:351-76.

[11] Tsai MY, Morton J. The effect of a spew fillet on adhesive stress distributions in laminated composite single-lap joints. Compos Struct 1995;32:123-31.

[12] Ashcroft IA, Abdel Wahab MM, Crocombe AD, Hughes DJ, Shaw SJ. The effect of environment on the fatigue of bonded composite joints. Part I: testing and fractography. Compos Part A Appl Sci 2001;32:45-58.

[13] Chaves FJP, da Silva LFM, de Castro PMST. Adhesively bonded T-joints in polyvinyl chloride windows. J Mater Des Appl 2008;222:159-74.

[14] Cheuk PT, Tong L. Failure of adhesive bonded composite lap shear joints with embedded precrack. Compos Sci Technol 2002;62:1079-95.

[15] Tsai MY, Morton J. The effect of a spew fillet on adhesive stress distributions in laminated composite single-lap joints. Compos Struct 1995;32:123-31.

[16] You M, Zheng Y, Zheng XL, Liu WJ. Effect of metal as part of fillet on the tensile shear strength of adhesively bonded single lap joints. Int J Adhes Adhes 2003:23:365-9.

[17] Sancaktar E, Nirantar P. Increasing strength of single-lap joints of metal adherends by taper minimization. J Adhes Sci Technol 2003;17:655-75.

[18] Boss JN, Ganesh VK, Lim CT. Modulus grading versus geometrical grading of composite adherends in single-lap bonded joints. Compos Struct 2003;62:113-21.

[19] McLaren AS, MacInnes I. The influence on the stress distribution in an adhesive lap joint of bending of the adhering sheets. Br J Appl Phys 1958;9:72-7.

[20] Fessel G, Broughton JG, Fellows NA, Durodola JF, Hutchinson AR. Evaluation of different lapshear joint geometries for automotive applications. Int JAdhes Adhes 2007;27:574-83.

[21] Campilho RDSG,Pinto AMG, Banea MD, Silva RF, da Silva LFM, Strength improvement of adhesively-bonded joints using a reverse-bent geometry, J Adhes Sci Technol, in press.

[22] Ávila AF, Bueno PO. Stress analysis on a wavy-lap bonded joint for composites. Int J Adhes Adhes 2004:24:407-14.

[23] Zeng Q, Sun CT. New design of a bonded lap joint. AIAA J 2001;39:1991-6.[24] Sancaktar E,

Simmons SR. Optimization of adhesively-bonded single lap joints by adherend notching. J Adhes Sci Technol 2000;14:1363-404

[25] Yan ZM, You M, Yi XS, Zheng XL, Li Z. A numerical study of parallel slot in adherend on the stress distribution in adhesively bonded aluminium single lap joint. Int J Adhes Adhes 2007;27:687-95.

[26] Campilho RDSG, Banea MD, Pinto AMG, da Silva LFM, de Jesus AMP, Strength prediction of single and double-lap joints by finite element modelling, Int J Adhes Adhes, in press, doi:10.1016/j.ijadhadh.2010.09.008.

[27] ASTM-E8M-04. Standard test methods for tension testing of metallic materi- als [Metric], 2004.

[28] da Silva LFM, da Silva RAM, Chousal JAG, Pinto AMG. Alternative methods to measure the adhesive shear displacement in the thick adherend shear test. J Adhes Sci Technol 2008;22:15-29.

[29] NF T 76-142. Méthode de preparation de plaques d'adhe'sifs structuraux pour la réalisation d'e' prouvettes d'essai de caractérisation, 1988.

[30] da Silva LFM, Adams RD. Measurement of the mechanical properties of structural adhesives in tension and shear over a wide range of temperatures. J Adhes Sci Technol 2005;19:109-41.

[31] ISO 11003-2:1993(E). Adhesives - determination of shear behavior of structural bonds, part II: Thick Adherend Tensile Test method, 1993.

[32] Crocombe AD. Global yielding as a failure criterion for bonded joints. Int J Adhes Adhes 1989;9:145-53.

[33] Schroeder JA. Photoelastic stress analysis of bonded lap shear joints having thermoplastic adherends. J Adhes 1990;32:89-103.

[34] Narasimhan S, Shenoil RA, Jeong HK. Three-dimensional stresses in adhe-sively bonded lap joints with non-identical adherends. J Mater Des Appl 2004;218:283-98 